\section{Intrapair associations in verbal discrimination learning*}

\author{
EUGENE A. LOVELACE, University of Virginia, Charlottesville, Va. 22904 \\ and \\ LYNN S. SCHULZ, University of Delaware, Newark, Del. 19711
}

The frequency theory of verbal discrimination (VD) learning predicts that intrapair associative relationships should have a detrimental effect on the learning of a VD list. Although prior tests have been mixed in outcome, the present study fails to support the prediction with respect to three types of associative relation: synonymic associates, antonvmic associates, and free associates of neither semantic class.

According to the frequency theory of verbal discrimination (VD) learning (Ekstrand, Wallace, \& Underwood, 1966), it should be detrimental to the acquisition of a VD list to have an associate of a correct item occur as an incorrect item in the list. Three tests of this prediction for intrapair associative relationships have been reported. Studies by Eberlein \& Raskin (1968) and Fulkerson \& Kausler (1969) indicated no systematic effect of intrapair associative relationships, although they provide evidence that interpair associative relationships are detrimental. Intrapair associations have been reported to interfere with VD acquisition in a series of four experiments by Palermo \& Ullrich (1968).

The present research was designed to specify the effects of intrapair associations with respect to three types of relationships: synonymic associates, antonymic associates, and free associates falling into neither of these semantic classes. Comparison of these three classes of associative relationship is of added interest, since false recognition has been readily demonstrated for synonyms and associates, but not antonyms (e.g., Grossman \& Eagle, 1970).

\section{EXPERIMENT 1}

Design and Materials

Each S learned a 30-pair VD list. Intrapair associative relationship was a between-Ss variable, with such associations present in the experimental condition and absent in the control condition. Type of associative relationship was varied within Ss; in the experimental condition, 10 of the 30 pairs were synonymic associates, 10 were

*The authors express their thanks to Mr. Robert B. Hampson. Jr.. for his assistance with the conduct of Experiment 2. Requests for reprints should be sent to Eugene A. Lovelace, Psychology Department-Gilmer Hall, University of Virginia, Charlottesville, Va. 22901. antonymic associates, and 10 were free associates that were neither synonyms nor antonyms.

Items used in the experimental condition were selected from the associative norms of Palermo \& Jenkins (1964). The sublists of 10 pairs were approximately equated for strength of the associative connections and for number of primary, secondary, and tertiary associates employed.

For each pair in the experimental condition, one member was chosen to be correct for half the $S s$ in that condition, while the other item was designated as correct for the remaining Ss. For each of these two experimental lists, a corresponding control list was derived by replacing the incorrect member of each pair with a word judged to be minimally related to other words in the list. Each replacement word began with the same letter as the incorrect item it replaced and was roughly equated with that item in terms of letter and syllabic length, as well as Thorndike-Lorge (1944) frequency. The designation of sublists in the control condition was nominally determined by the intrapair relationships for corresponding pairs in the experimental condition. Subjects

The $S$ s were 40 male undergraduates at the University of Virginia. None had had prior experience with VD learning. Procedure

The Ss were alternately assigned to experimental and control conditions, 20 Ss per condition. Materials were presented at a 2-sec rate on a Lafayette Model 303B memory drum; the intertrial interval was 4 sec. Learning was by the anticipation method; after the presentation of each pair, the pair was shown again with the correc member underscored. Four versions of each list were employed to vary the order of presentation. Within each trial, half the correct items appeared on the right and half on the left; over trials, each item occurred equally often in the two positions. Eight trials of VD learning were given, after which Ss were asked for written recall of items in any order.

Results

Analysis of errors over the first five trials showed no significant effect of the experimental vs control comparison, $F(1,38)=1.40$, but there was a significant interaction of Experimental-Control by Sublist by Trials, $F(8,304)=2.18, p<.05$. This interaction apparently derived from the fact that the synonymic sublist of the experimental condition showed performance well above chance on the first (guessing) trial but improved relatively slowly thereafter. The mean numbers of errors on Trials 1-5 for the synonymic, antonymic, and free-associate sublists of the experimental condition were $\mathbf{1 6 . 9 5}$ $(\mathrm{SD}=5.85), 17.00 \quad(\mathrm{SD}=6.01)$, and $16.40(\mathrm{SD}=6.82)$, respectively. For the corresponding sublists in the control condition, these means were $14.80(\mathrm{SD}=5.92), 15.10(\mathrm{SD}=4.95)$, and $15.10(\mathrm{SD}=4.83)$.

There was little difference in recall of correct items following the VD task for the experimental and control conditions, with the mean recall being $17.05(S D=2.98)$ and 17.35 $(\mathrm{SD}=3.73)$, respectively. The number of incorrect items recalled was significantly greater for the experimental condition with a mean recall of $16.65 \quad(\mathrm{SD}=3.07)$, as compared to the control condition with a mean recall of 11.25 $(\mathrm{SD}=4.30), \quad \mathrm{t}(38)=4.58, \quad \mathrm{p}<.01$. The superior recall of incorrect items in the experimental condition resulted from associatively related items being recalled together, i.e., the correct and incorrect members of an associatively related pair were recalled in adjacent output positions. An average of 16.15 pairs were recalled in this manner in the experimental condition, whereas the control condition had a mean of only 8.60 pairs recalled in adjacent output positions.

Item recall for the experimental condition was examined with respect to type of associative relationship. Within each of the three sublists, the mean number of pairs recalled in adjacent positions was nearly identical to the mean number of correct items recalled. Recall differed between sublists, however; the mean number of pairs recalled were $6.10,5.60$, and 4.45 for the free-associate, synonymic, and antonymic sublists, respectively, $F(2,38)=6.56, \quad p<.01$. Pairwise comparisons by $t$ tests indicated that recall was poorer for antonyms than for synonyms, $t(38)=2.47, p<.02$, or free associates, $t(38)=3.24$, $\mathrm{p}<.01$. Recall of synonyms and free associates did not differ significantly. EXPERIMENT 2 Method

The second experiment was a simple replcication of Experiment 1 by a 
different $E$, except that no item recall was taken following the VD task.

Results

The control condition showed slightly poorer performance than did the experimental condition. Analysis of errors over the first five trials indicated that this difference did not reach statistical significance, $F(1,38)=3.62, p>.05$. There was no significant rifference due to type of associative relationship (sublist), and no interactions involving sublist were significant. The mean numbers of errors on Trials 1-5 for the synonymic, antonymic, and free-associate sublists of the experimental condition were $18.60(\mathrm{SD}=3.46), 18.60(\mathrm{SD}=6.07)$, and $18.45(S D=4.22)$, respectively. For the corresponding sublists in the control condition, these means were $21.00(\mathrm{SD}=3.84), 19.80(\mathrm{SD}=3.56)$, and $20.50(\mathrm{SD}=3.94)$.

\section{DISCUSSION}

The present results do not confirm predictions from the frequency theory of VD learning regarding intrapair associative relationships; indeed, the data from Experiment 2 are not even in the predicted direction. It should be noted that the studies of Palermo \& Ullrich (1968) differ procedurally from the present study and other research yielding negative results.
Palermo and Ullrich varied the presence vs absence of intrapair relationship as a within-list variable, while in all other investigations, this was a between-Ss manipulation. This suggests that the results obtained by Palermo and Ullrich may very well have been effects of strategy or selective and differential attention to two discernible sublists.

In agreement with Eberlein \& Raskin (1968) and Fulkerson \& Kausler (1969), the present findings make it seem unlikely that any increase in difficulty of learning VD pairs results from the presence of intrapair associative relationships. It would further appear that the rate of VD learning is not determined by the semantic nature of intrapair relationships, e.g., synonymic or antonymic pairs.

It is interesting to note that the items from the three sublists in the experimental condition were not equally recallable following VD acquisition. Since no differential rate of VD learning was observed for these sublists, it seems that the "learning" which permits recall of jtems has no facilitating effect on performance in the VD task. This differential learning reflected in recall of items does parallel, however, the finding that false recognition of items occurs when a synonym or associate of that word was presented previously, but not when an antonym has occurred (Grossman \& Eagle, 1970).

\section{REFERENCES}

EBERLEIN, E.. \& RASKIN, D. C. Intrapair and interpair associations in verbal discrimination learning. Psychonomic Science, 1968, 14, 145-146.

EKSTRAND, B. R.. WALLACE, W. P., \& UNDERWOOD, B. J. A frequency theory of verbal-discrimination learning. Psychological Review, 1966, 73, 566-578.

FULKERSON, F. E.. \& KAUSLER, D. H. Effects of intrapair and interpair bidirectional associates on verbal-discrimination learning. Joumal of Verbal Learning \& Verbal Behavior, $1969,8,307-310$.

GROSSMAN, L., \& EAGLE, M. Synonymity, antonymity and association in false recognition responses. Journal of Experimental Psychology, 1970, 83. 244-248.

PALERMO, D. S., \& JENKINS, J. J. Word association norms. Minneapolis: University of Minnesota Press, 1964.

PALERMO. D. S., \& ULLRICH, J. R. Verbal discrimination leaming as a function of associative strength between the work-pair members. Journal of Verbal Learning \& Verbal Behavior, 1968, 7. 945-952.

THORNDIKE, E. L., \& LORGE, I. The teacher's word book of 30,000 words. New York: Bureau of Publications, Teachers College, Columbia University, 1944.

\section{CURRENT LITERATURE ON VERBAL LEARNING}

BROWN, A. L., \& LLOYD, B. B. (School of African and Asian Studies, University of Sussex, Sussex BN 1, England). Criteria of success in a developmental study of oddity learning. British Journal of Psychology, 1971, 62, 21-26.

DEY, M. K. (Jersey City State College, Jersey City, N.J. 07305). Reminiscence in paired-associate learning. British Journal of Psychology, 1971, 62, 41-51.

HABER, R. N. (University of Rochester, Rochester, N.Y. 14627). An alphanumeric display program for a PDP-8. Behavior Research Methods \& Instrumentation, 1971, $3,141-145$.

LOEWENTHAL, K. (Department of Social Science and Humanities, City University, London, England). A study of imperfectly acquired vocabulary. British Journal of Psychology, 1971, 62, 225-233.

McGLAUGHLIN, A. (University of Hull, Hull, England), \& DALE, $H$. C. A. Stimulus similarity and transfer in long-term paired-associate learning. British Journal of Psychology, 1971, 62, 37-40.

MEUNIER, G. F. (Ball State University, Department of General \& Experimental Psychology,
Muncie, Ind. 47306 ). Pronounceability, rehearsal time, and the primacy effect of free recall. Joumal of Experimental Psychology, 1971, 88, 123-127.

PETERS, K. G., \& DENNY, J. P. (University of Western Ontario, London, Ontario, Canada). Labeling and memory effects on categorizing and hypothesizing behavior for biconditional and conditional conceptual rules. Journal of Experimental Psychology, 1971, 87, 229-233.

RIMM, D. (Arizona State University, Tempe, Ariz. 85281), ROESCH, R., PERRY, R., PEEBLES, C. Effects of blank versus noninformative feedback and "right" and "wrong" on response repetition in paired-associate learning. Journal of Experimental Psychology, 1971, 88, 26-30.

RUNQUIST, W. N. (University of Alberta, Edmonton 7, Alberta, Canada). Ordinal position of formal similarity among stimuli. Journal of Experimental Psychology, 1971, 87, 270-273.

SCHWARTZ, M. (University of Wisconsin, Madison, Wis. 53706). Stimulus frequency and meaningfulness varied independently in the learning of word-number pairs. Journal of Experimental Psychology, 1971, 87, 289-291.

SHEEHAN, P. W. (University of New England, Armidale, N.S.W. Australia). The role of imagery in incidental learning. British Journal of Psychology, 1971, 62, 235-243.

SMITH, S., \& JENSEN, L. (Brigham Young University, Provo, Utah 84601). Test of the frequency theory of verbal discrimination learning. Journal of Experimental Psychology, 1971, 87, 46-51.

STRAND, B. Z. (Georgetown University, Washington D.C. 20007). Further investigation of retroactive inhibition in categorized free recall. Journal of Experimental Psychology, 1971, 87, 198-201.

YUILLE, J. C. (University of British Columbia, Vancouver 8 , Canada). Does the concreteness effect reverse with delay? Journal of Experimental Psychology, 1971, 88, 147-148.

ZERDY, G. A. (Computer Science Center, University of Maryland, College Park, Md. 20742). Incidental retention of recurring words presented during auditory monitoring tasks. Journal of Experimental Psychology, 1971, 88, 82-89. 